\title{
Brasilia: del Plan a la Realidad, 50 Años Después
}

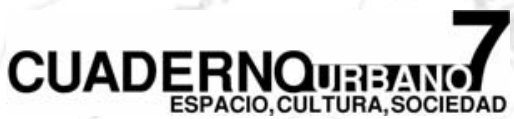

Reportaje de Ciudades

Por Anamaria de Aragão Costa Martins
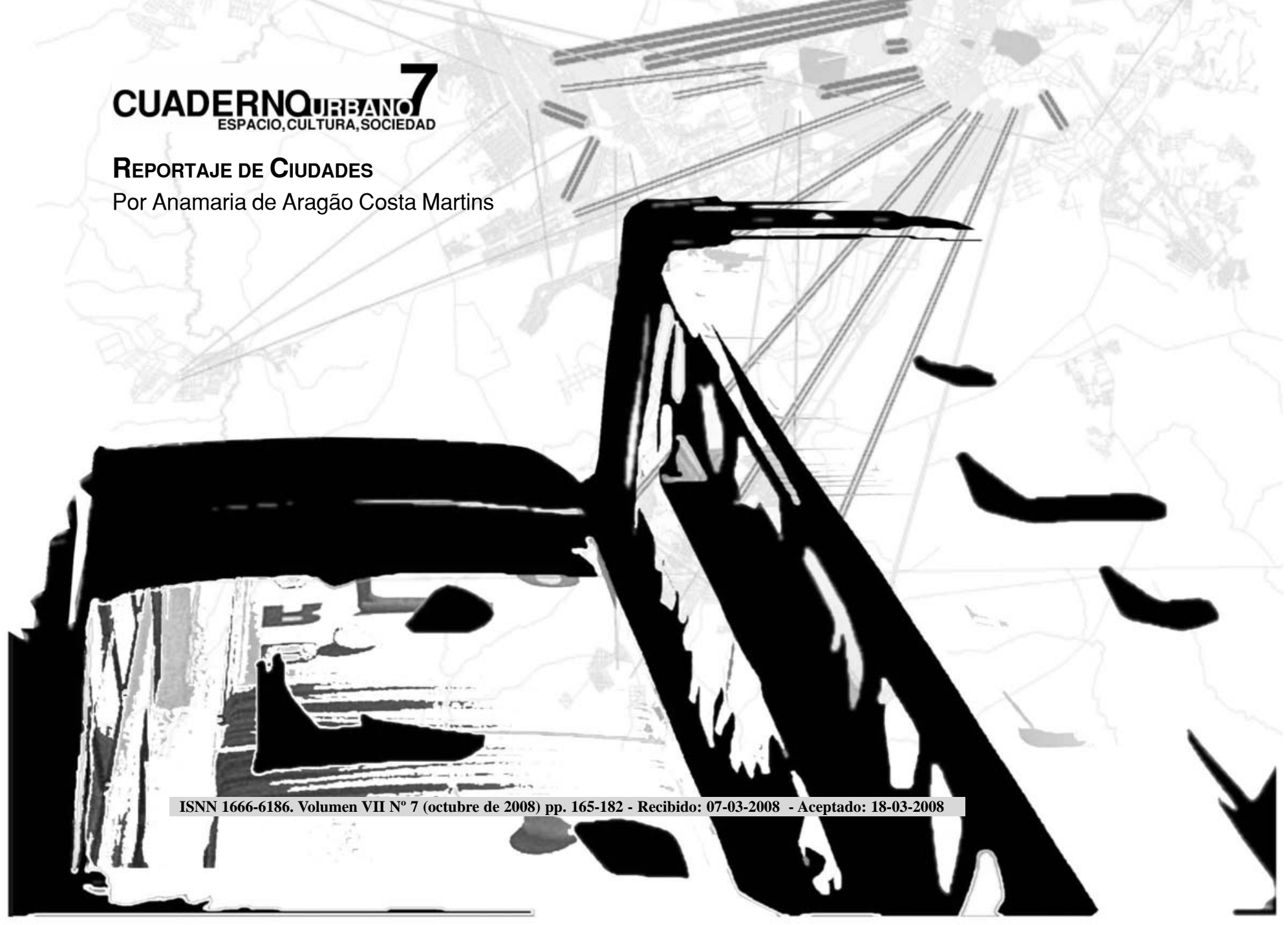


\section{Brasilia, del plan a la realidad,}

\section{Anamaria de Aragão Costa Martins}

Arquitecta por la Universidad de Brasilia y doctora en Urbanismo por la Universidad Politécnica de Catalunya. Urbanista del Gobierno del Distrito Federal desde 1997. Entre 2001 y 2004, colaboró con Joan Busquets en proyectos de transformación urbana en Francia, Portugal y Holanda. Durante 2007, fue subsecretaria de Planeamiento Urbano del Distrito Federal. Actualmente, desarrolla los proyectos urbanos estratégicos de la Secretaría de Desarrollo Urbano y Medio Ambiente del Distrito Federal.

\section{Resumen}

Este artículo presenta las principales transformaciones de Brasilia pasados 50 años del Plan Urbanístico para la capital brasileña elaborado por Lucio Costa. Cómo conciliar la protección de la Ciudad Patrimonio de la Humanidad con la necesidad de alteración de los principios del urbanismo racionalista presentes en el Plan constituye uno de los principales retos de las acciones públicas. Además, el proceso de metropolización, según un modelo de dispersión urbana, presenta un conjunto de problemas a ser tratado por el planeamiento territorial y urbano. Partiendo de la descripción del proceso de crecimiento de Brasilia hacia la formación de la aglomeración actual, el artículo describe las principales directrices urbanísticas adoptadas en planes y proyectos recientes.

\section{Abstract}

\section{Brasilia: From plan to reality, 50 years later}

This article presents the main transformations of Brasilia, 50 years after the development of the Urban Plan for the Brazilian capital, designed by Lucio Costa. How to reconcile the preservation of a World Heritage City, with the revision of many principles of rationalist urbanism contained in the Plan seems to be one of the many challenges to public actions. Besides, the metropolization process in course, following an urban sprawl model, presents several problems to be solved through regional and urban planning. Starting with the description of Brasilia's growth process towards becoming the present urban agglomeration, the article presents the main urban guidelines developed by recent plans and projects.

Cuaderno Urbano. Espacio, Cultura, Sociedad - Vol. VII - № 7 (Octubre 2008) - pp. 165-182. ISNn 1666-6186 


\section{INTRODUCCIÓN}

En 2007 se celebraron los 50 años del Plan Urbanístico de Brasilia, la cara más conocida de la historia de la capital brasileña, planeada en 1957 y construida en tan sólo dos años. Brasilia es un mito de la planificación urbana, por ser un ejemplo de los principios del urbanismo racionalista, seguidos por Lucio Costa. Materializó la utopía de una generación de planeadores. Coordinó con el urbanismo una arquitectura del más alto nivel, consagrando otro mito internacional, Oscar Niemeyer. ¿Pero qué ha pasado con la ciudad 50 años después?

En la visión del territorio contenida en el Plan, Brasilia alcanzaría los 500.000 habitantes que ocuparían el área del plan piloto. Sólo entonces, se iniciaría la formación de ciudades satélites. Sin embargo, ya en 1958, dos años antes de la inauguración de la capital, un nuevo núcleo - Taguatinga - fue implantado y sobre la fecha de la inauguración de la capital un segundo núcleo - Sobradinho, inició su ocupación. Así, antes de que el Plan Piloto de Lucio Costa se consolidara como ciudad, Brasilia ya era una aglomeración de núcleos que circundaban su área central (figura l).

Las dinámicas y las promesas de la nueva capital atrajeron gran cantidad de inmigrantes. Entre 1970 y 1985, Brasilia creció por año alrededor de 8,2\% (GDF/SEDUMA, 2007). En 1980 , la periferia concentraba $78,54 \%$ de la población y la población total de Brasilia ya superaba 1 millón de personas, distribuida en varias ciudades satélites (figura 1). Orientado por los planes territoriales, cuya principal premisa era el control de los recursos hídricos y saneamiento, los nuevos núcleos urbanos se ubicaron fuera de la cuenca del río Paranoá, es decir, por lo menos $15 \mathrm{~km}$ distante del área del Plan Piloto. Los planes subsiguientes reforzaron el argumento sanitarista y aumentaron las restricciones ambientales. La fragilidad del territorio de Brasilia ha sido, desde entonces, el argumento orientador

Anamaria de Aragão Costa Martins

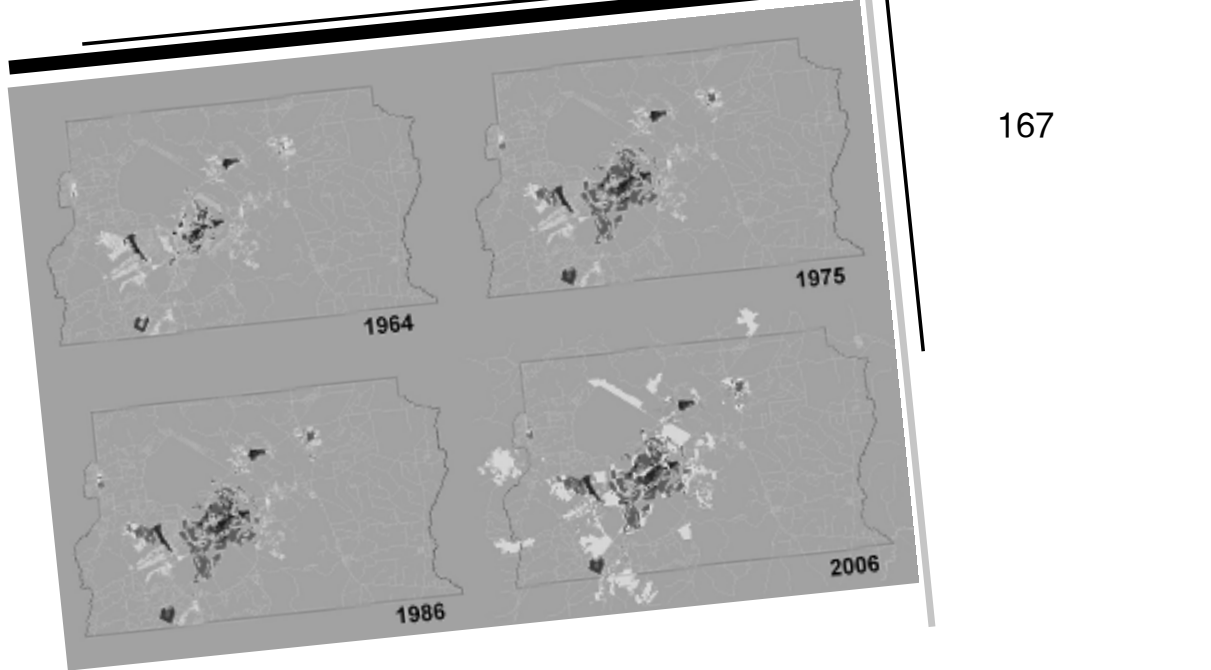




\section{Brasilia, del plan a la realidad,}

de las formas de organización urbana. Hoy 93\% del territorio se encuentra bajo algún tipo de protección ambiental.

Las tierras donde se ubicó Brasilia fueron parcialmente expropiadas, como una estrategia del período para frenar la especulación inmobiliaria. Con la tierra en propiedad pública, el gobierno pudo responder al crecimiento de la población (GDF/SEDUMA, 2007). En los años 70, se produjo una extensa producción de parcelas urbanizadas y, entre 1989 y 1994, se ofertaron 100 mil parcelas y fueron creados ocho nuevos núcleos urbanos, todas ciudades dormitorios de población dependiente del empleo concentrado en el área central.

Por una parte, estos programas generaron la expansión masiva de las áreas urbanizadas, siguiendo un modelo de ocupación extensiva y horizontal del territorio, pues se ofertaron sobretodo parcelas destinadas a la autoconstrucción de viviendas. Por otra parte, la iniciativa pública vino acompañada de cierto grado de planificación e infraestructura, por lo que hoy, en Brasilia, casi la totalidad de la población tiene agua (98\%) y saneamiento (93\%) (MANCINI, 2008).

Mientras la política pública relacionada con la vivienda se detuvo en las clases más pobres, los altos precios de los inmuebles en el área central y los deseos de la clase media de vivir en casas siguiendo la tendencia cultural y económica de las cla168 las urbanizaciones dispersas: en primer plano, el área de viviendas unifamiliares de Vicente Pires, irregular; al fondo, el barrio de torres residenciales de Águas

Claras, planeado. Foto: Luis Antonio Reis, SEDUMA, 2007. ses emergentes, han fomentado un mercado inmobiliario paralelo e ilegal: la reparcelación de tierras rurales, tanto las de propiedad pública como privada, bajo la forma de condominios unifamiliares dis-

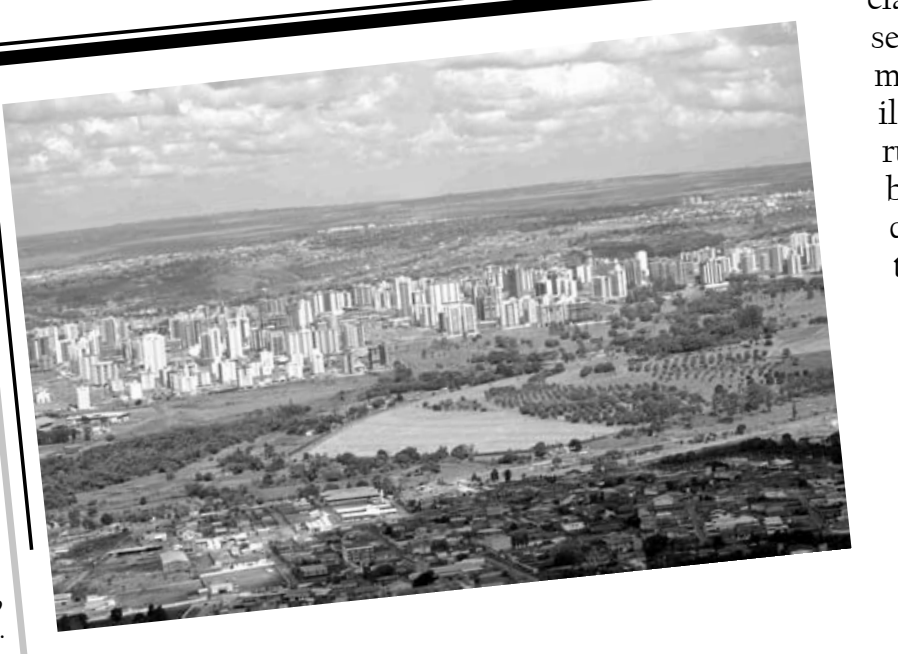
tantes del centro urbano (figura 2).

Estos barrios de clase media han cambiado las direcciones del planeamiento territorial, pues ocuparon una porción del territorio históricamente reservada para la construcción de un lago que serviría al abastecimiento futuro de la capital. Desde 1997,

Cuaderno Urbano. Espacio, Cultura, Sociedad - Vol. VII - № 7 (Octubre 2008) - pp. 165-182. ISNn 1666-6186 


\section{0 años después}

se intenta regularizar estas propiedades, para que se les pueda obligar a mitigar los impactos ambientales (muchas urbanizaciones se encuentran en áreas frágiles, contaminado manantiales, por ejemplo). Pero la indefinición de la situación de parte de las tierras de la capital (46,7\% de las tierras sigue siendo de propiedad privada, pues no se han pagado aún parte de las indemnizaciones y hay litigios en relación a algunas propiedades) dificulta la regularización (GDF/SEDUMA, 2007). Tan sólo en 2007, por decisión de la justicia, estos propietarios han comenzado a pagar los impuestos sobre la tierra urbana.

Así, el área central de Brasilia que abarca el Plan Piloto de Lucio Costa y nuevos barrios planeados en los años 80 por este urbanista en su documento "Brasilia revisitada" comprende tan sólo 12,48\% de la población de Brasilia (datos de 2006) (GDF/SEDUMA, 2007).

El entorno inmediato al área central se caracteriza por barrios eminentemente residenciales de clase alta, de baja densidad, en los bordes del lago Paranoá, que concentran 2,58\% de la población (figura 3). Contrasta con este modelo extensivo, la porción sudoeste del territorio, de ciudades y barrios distantes por lo menos $15 \mathrm{~km}$ del área central, donde predomina la ocupación intensiva del suelo y altas densidades. En una mancha urbana equivalente a la del área central, vive una población tres veces más grande (figura 4) (GDF/ SEDUMA, 2007). En las distancias superiores a $20 \mathrm{~km}$, se dibuja la mancha difusa de urbanizaciones residenciales.

La Brasilia de la que hablamos hoy es, por lo tanto, mucho más grande y com-

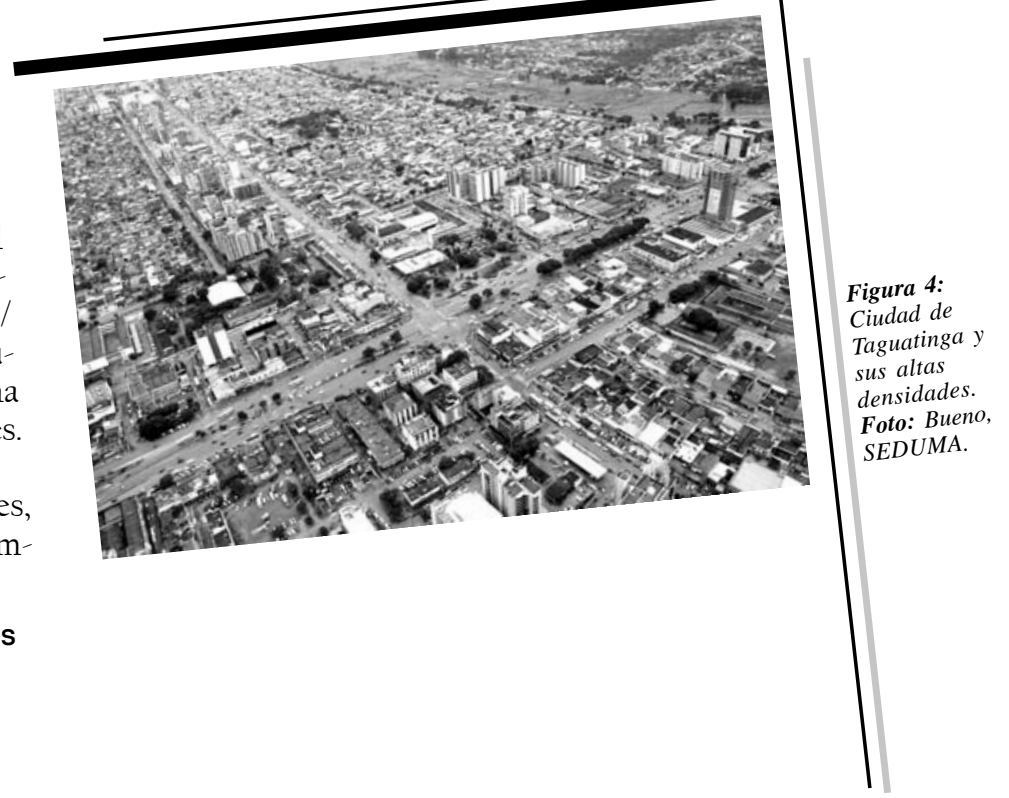

Anamaria de Aragão Costa Martins 


\section{Brasilia, del plan a la realidad,}

pleja que el Plan Piloto de Lucio Costa. Inserta en la unidad de la federación denominada Distrito Federal, comprende 29 núcleos urbanos, algunos ya perceptibles como ciudades y muchos todavía organizados como barrios dependientes del área central.

\section{BRASILIA 50 AÑOS DESPUÉS}

\subsection{La Brasilia Patrimonio de la Humanidad}

El reconocimiento de la Unesco, con la inscripción de Brasilia como Patrimonio Cultural de la Humanidad en 1992, ha orientado una política de preservación del área del Plan Piloto de Lucio Costa.

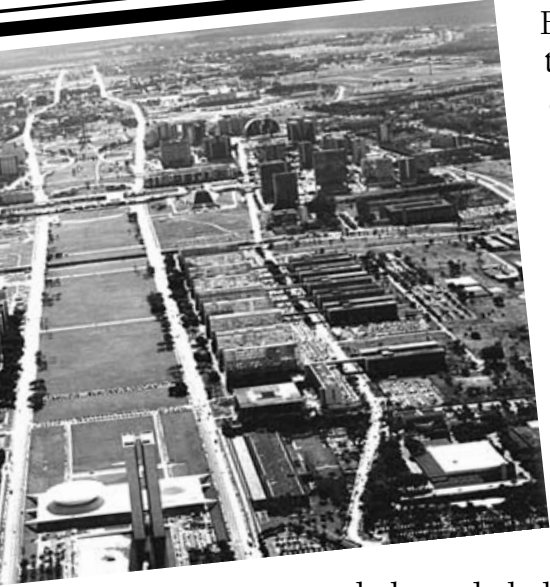

El área de $112,5 \mathrm{~km} 2$ es el conjunto urbano protegido más grande. La legislación de protección, sin embargo, impone restricciones tanto a áreas con gran valor arquitectónico (los grandes monumentos proyectados por Oscar Niemeyer) y urbanístico (la Explanada de los Ministerios, la Plaza de los Tres Poderes) como a otras áreas en proceso de transformación (como el Sector de Industrias Gráficas), o en proceso de degradación (la vía w3 sur, la más antigua Avenida de la Capital) que requieren transformaciones urgentes.

La preservación de las cuatro escalas que estructuran la concepción de la ciudad es la base de la legislación de preservación. Nuevas dinámicas en los espacios urbanos son, con todo, la constatación de que los ciudadanos y el mercado encuentran sus propias reglas en la ciudad, muchas veces diferentes de lo planeado.

La escala monumental comprende el área sede de la administración federal, donde se manifiesta el carácter cívico de la ciudad. Este espacio se encuentra sobrecargado por la cantidad de zonas de aparcamiento que vulgarizan el paisaje (figura 5).

La escala residencial (figura 6) está materializada en las unidades de vecindad, un conjunto de cuatro manzanas que reúnen bloques de viviendas emplazados en medio de es-

Cuaderno Urbano. Espacio, Cultura, Sociedad -Vol. VII - № 7 (Octubre 2008) - pp. 165-182. ISnN 1666-6186 


\section{0 años después}

pacios verdes, con áreas de comercio y parcelas destinadas a instituciones culturales, de ocio y la enseñanza - la biblioteca, la escuela, la iglesia, el club, el cine- L La vida contemporánea, no obstante, no ha seguido los estándares basados en las relaciones de proximidad:

* los cines se encuentran en centros comerciales por lo que las parcelas tienden a ser ocupadas con usos comerciales o institucionales;

* la enseñanza privada en Brasil presenta mejores resultados que la pública; así como la población del área del Plan Piloto es de clase media, los hijos de las familias acaban buscando escuelas privadas, no siempre cercanas de la residencia;

* el comercio local ha tendido a especializarse, abarcando un mercado más amplio que el de la unidad de vecindad.

La escala gregaria (figura 7) ocurre sobre todo en los sectores centrales donde se concentra gran parte de los puestos de trabajo. La sectorización estricta que prohíbe la residencia e incentiva las actividades terciarias genera una gran concentración humana en estas áreas durante la semana y la total ausencia de utilización del área en los fines de semana y por la noche.

La escala bucólica es representada por los amplios espacios libres que caracterizan el Plan Piloto de Lucio Costa como ciudad parque. Estos espacios generan grandes distancias entre las áreas urbanizadas, dificultando soluciones de transporte. Además, los espacios sinfunción acaban como depósito de residuos de la construcción y se degradan (figura 8) (MARTINs, 2007).

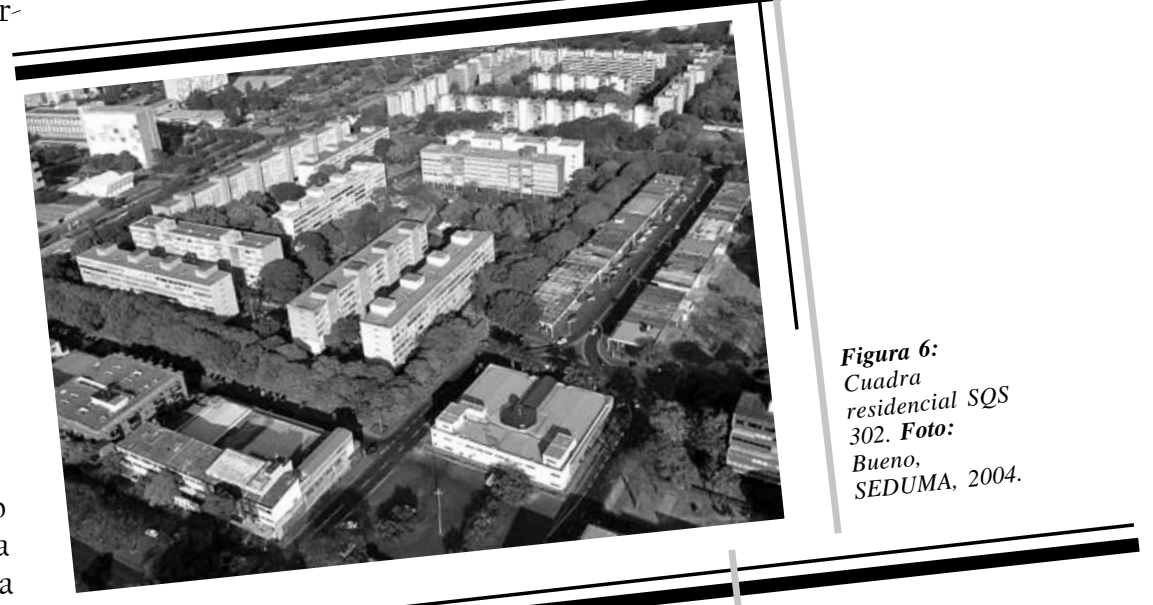

Anamaria de Aragão Costa Martins

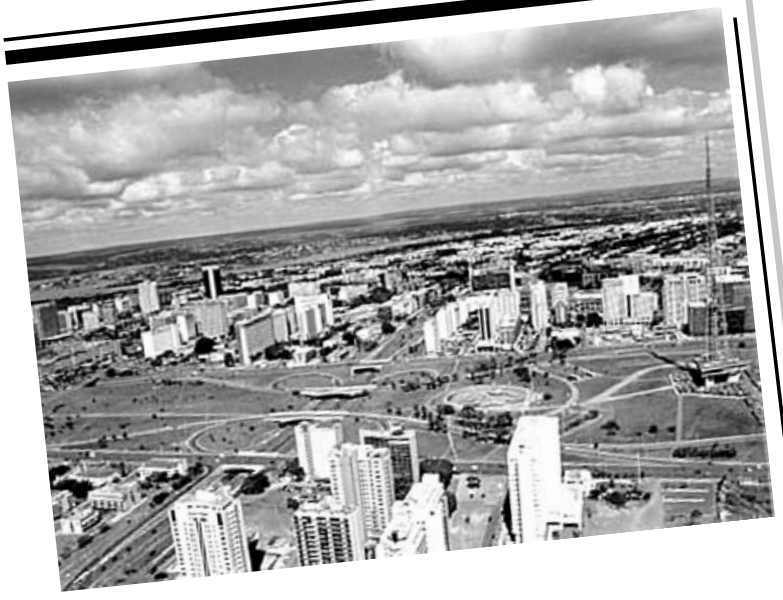



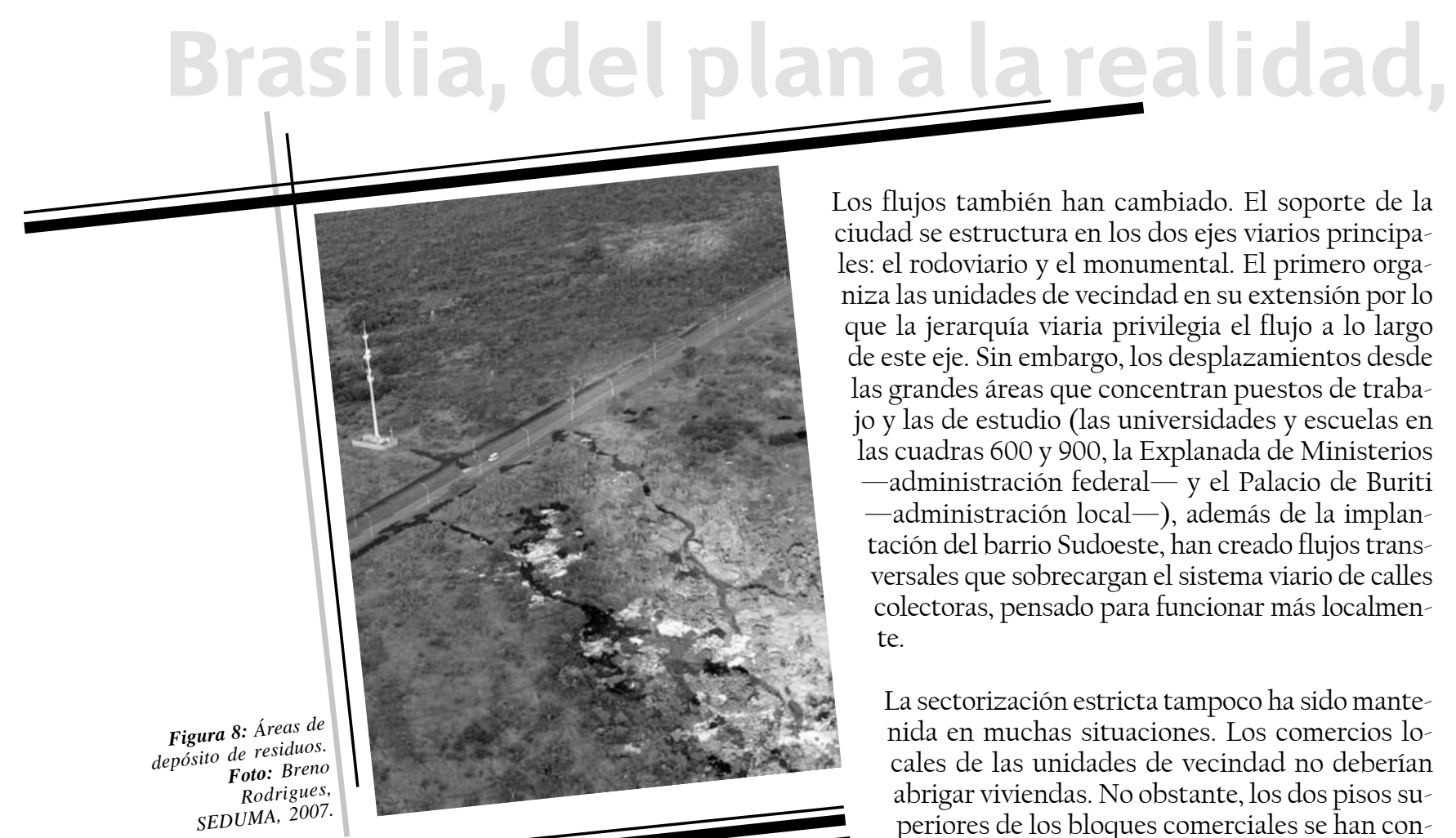

Los flujos también han cambiado. El soporte de la ciudad se estructura en los dos ejes viarios principales: el rodoviario y el monumental. El primero organiza las unidades de vecindad en su extensión por lo que la jerarquía viaria privilegia el flujo a lo largo de este eje. Sin embargo, los desplazamientos desde las grandes áreas que concentran puestos de trabajo y las de estudio (las universidades y escuelas en las cuadras 600 y 900, la Explanada de Ministerios - administración federal- y el Palacio de Buriti —administración local一), además de la implantación del barrio Sudoeste, han creado flujos transversales que sobrecargan el sistema viario de calles colectoras, pensado para funcionar más localmente.

La sectorización estricta tampoco ha sido mantenida en muchas situaciones. Los comercios locales de las unidades de vecindad no deberían abrigar viviendas. No obstante, los dos pisos superiores de los bloques comerciales se han convertido en pequeños estudios que abrigan parte de la población que no puede pagar los altos precios de la vivienda convencional y busca otras alternativas irregulares.

La preservación rígida de aspectos criticables del urbanismo del movimiento moderno, como la sectorización estricta de funciones, la jerarquía viaria que genera la ruptura del tejido urbano por calles moldeadas como autopistas, las dificultades de manejar soluciones para transporte, tráfico y movilidad peatonal derivadas la fragmentación del tejido urbano, la degradación ambiental de los espacios libres sin función convertidos en depósito de basura demuestran la necesidad

Cuaderno Urbano. Espacio, Cultura, Sociedad -Vol. VII - № 7 (Octubre 2008) - pp. 165-182. ISNn 1666-6186 
de proponer una visión más flexible de los parámetros de la preservación. Sin embargo, hay todavía una gran resistencia por parte de planeadores y defensores del urbanismo moderno en proponer cambios para el área del Plan Piloto de Lucio Costa.

\subsection{La Brasilia metropolitana y los problemas de la dispersión urbana}

Diferentes autores han constatado el alto grado de dispersión urbana de la capital brasileña. Midiendo las distancias casa-trabajo, BerTAud y Malpezzi (2003) han considerado Brasilia la capital más dispersa al compararla con otras 48 capitales internacionales. De la misma forma, otros autores han observado el gradiente de densidad de población decreciente de Brasilia del centro respecto de la periferia, constatando que la periferia más distante (los núcleos que distan más de $20 \mathrm{~km}$ del centro) es más densa que el área central, a modo inverso de otras ciudades (MANcINI, 2008).

La dispersión urbana en Brasilia presenta un conjunto de resultados negativos para la población: la tarifa más cara de transporte público del país, largos atascos (figura 9), el gasto de una proporción significativa de los ingresos de los más pobres en transporte, excesivos tiempos de desplazamiento diarios.

En Brasilia, los principales motivos de viajes son el trabajo (53\%) y el estudio (26\%). Como el trabajo se encuentra concentrado en el área central $(82 \%)$, se obser-

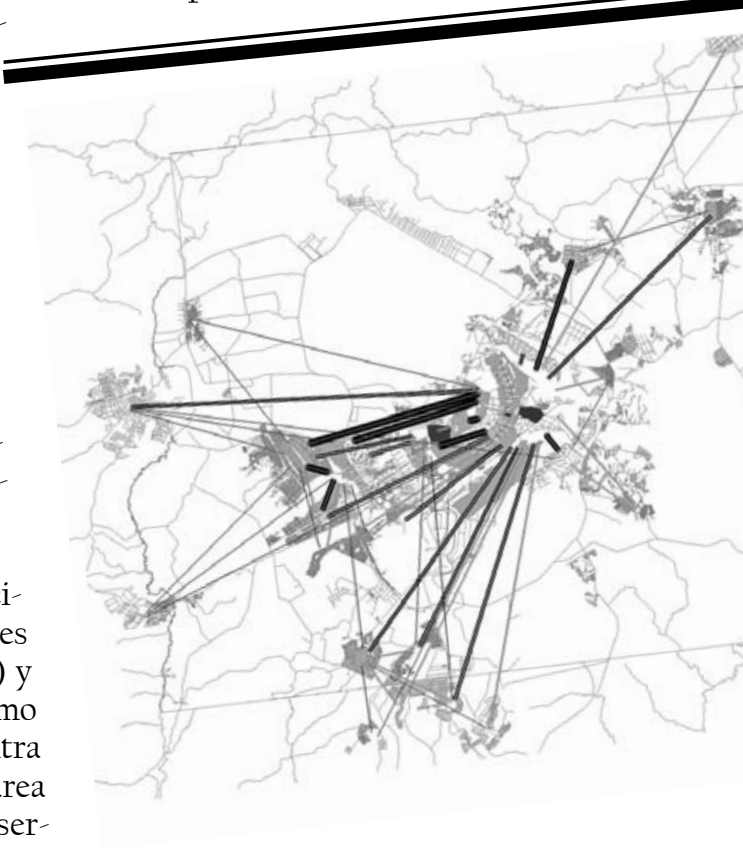

\section{Anamaria de Aragão Costa Martins}




\section{Brasilia, del plan alarealidad,}

van altos índices de movilidad pendular (figura 10). Se observa además el incremento de la movilidad privada. Según datos de 2000 (CODEPLAN, 2000), 54,59\% de la población tiene un coche. En 1990, 842.000 personas hacían sus desplazamientos diarios en coche y en 2000 ya eran 1.069.204.

La sobrecarga en el sistema viario estructural y la necesidad creciente de áreas de aparcamiento en el área central son consecuencias de la utilización de vehículos privados en lugar de transporte público.

La opción por el transporte privado resulta de la ineficiencia del sistema de transporte colectivo. Como son dimensionados a partir del índice de pasajeros por kilómetro, en áreas con bajas densidades y frente a un modo de ocupación extensivo del suelo, los sistemas de transporte público tienden a ser muy costosos e ineficientes como en el caso de Brasilia.

Como consecuencia de la dispersión de la residencia y de la movilidad pendular, las autopistas han generado nuevos usos. Se observan nuevos polos comerciales, cercanos a las urbanizaciones eminentemente residenciales. Áreas industriales y grandes superficies comerciales buscan la accesibilidad y visibilidad generada por las calles de la Brasilia metropolitana (MARTINs, 2006).

La movilidad diaria ocurre no sólo entre los núcleos internos del Distrito Federal. Los municipios fronterizos han doblado de tamaño en la última década. Entre 2000 y 2006 hubo una expansión urbana del orden de 28,90\% (GDF/SEDUMA, 2007). Una parte de la población del Distrito Federal se ha desplazado a estas áreas donde el precio de la tierra es más bajo. Los riesgos del crecimiento de estos municipios sobre el medio ambiente son latentes. El más grande - Águas Lindas- se encuentra cerca del punto más importante de abastecimiento de agua. La falta de infraestructura en estas áreas genera serios riesgos de contaminación de la cuenca. Como administrativamente pertenecen a otros Estados el Distrito Federal no invertía recursos en ellos. A su vez, por su relación con Brasilia, no contaban con las prioridades presupuestarias de sus Estados. Vivían en un umbral económico y administrativo revertido en los últimos años con las inversiones que el Gobierno del Distrito Federal ha hecho sobretodo en saneamiento, seguridad y educación.

Así, la Brasilia metropolitana es una ciudad difusa, que incluye el Distrito Federal y su entorno, donde viven más de 2 millones de habitantes.

Cuaderno Urbano. Espacio, Cultura, Sociedad-Vol. VII - № 7 (Octubre 2008) - pp. 165-182. ISNn 1666-6186 


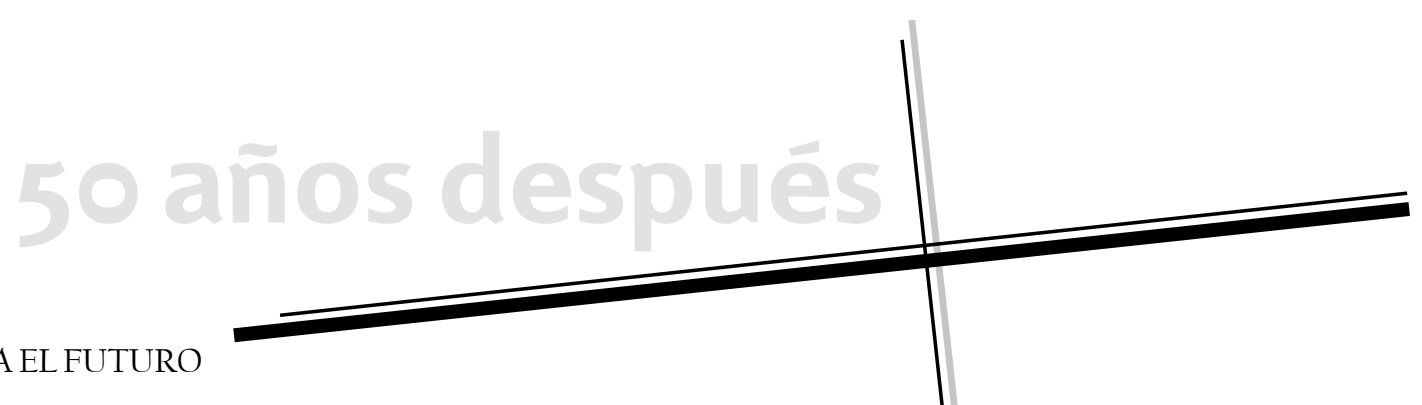

El Plan Director de Ordenación del Territorio, en proceso de aprobación, tiene el desafío de buscar nuevas soluciones para el territorio marcado por la dispersión de la residencia, y el empleo concentrado en el área central. Se propone una serie de estrategias basadas en intervenciones de gran escala sobre el territorio, que complementan la parte más normativa del plan.

Por una parte, el plan define las zonas urbanas, rurales y de interés ambiental, siguiendo la tradición del planeamiento. Para frenar el proceso de dispersión urbana, el plan introduce una innovación - la zona de contención urbana- que define la transición entre el urbano y el rural, tocando sobre todo espacios con restricciones ambientales que sufren presiones inmobiliarias. En esta zona, los propietarios que decidan parcelar el suelo tendrán un impuesto progresivo, mientras que quienes decidan mantenerlos como rurales, pagarán menos. Se incentiva o bien la gran propiedad rural, o bien la parcelación más densa, evitando la formación de nuevas urbanizaciones a modo de pequeñas estancias, que han contribuido a la dispersión urbana.

Buscando la descentralización del empleo, cambiando la dirección de los desplazamientos diarios, el plan propone la creación de nuevas centralidades en el territorio. Por una parte, se proponen centra-lidades primarias - las áreas de dinamización urbana - en los sectores más poblados del territorio, fuera del área central. Luego, se proponen centralidades secundarias, y al articularlas se idealiza la red estructural de transporte colectivo para un horizonte temporal de veinte años, aún más amplio que el del propio plan.

Las centralidades primarias fueron definidas en sitios estratégicos: 1) donde ya hay algún embrión de actividades económicas, 2) en espacios con gran accesibilidad a escala metropolitana y 3) en sectores donde vive la mayoría de la población. Se propone en estas áreas la intensificación del uso del suelo, la reorganización del sistema de transporte, la recalificación de los espacios libres y el incentivo a la multi-funcionalidad (figura ll).

Las centralidades secundarias constituyen tanto polos en los alrededores de las estaciones de integración del transporte colectivo, con comercio, servicio y viviendas, como anillos de actividades que integrarán las urbanizaciones dispersas (figura ll).

Para atender a la demanda de vivienda en los próximos años, se proponen nuevas áreas habitacionales, por una parte aprovechando los vacíos intra-urbanos y por otra, como ex-

Anamaria de Aragão Costa Martins 


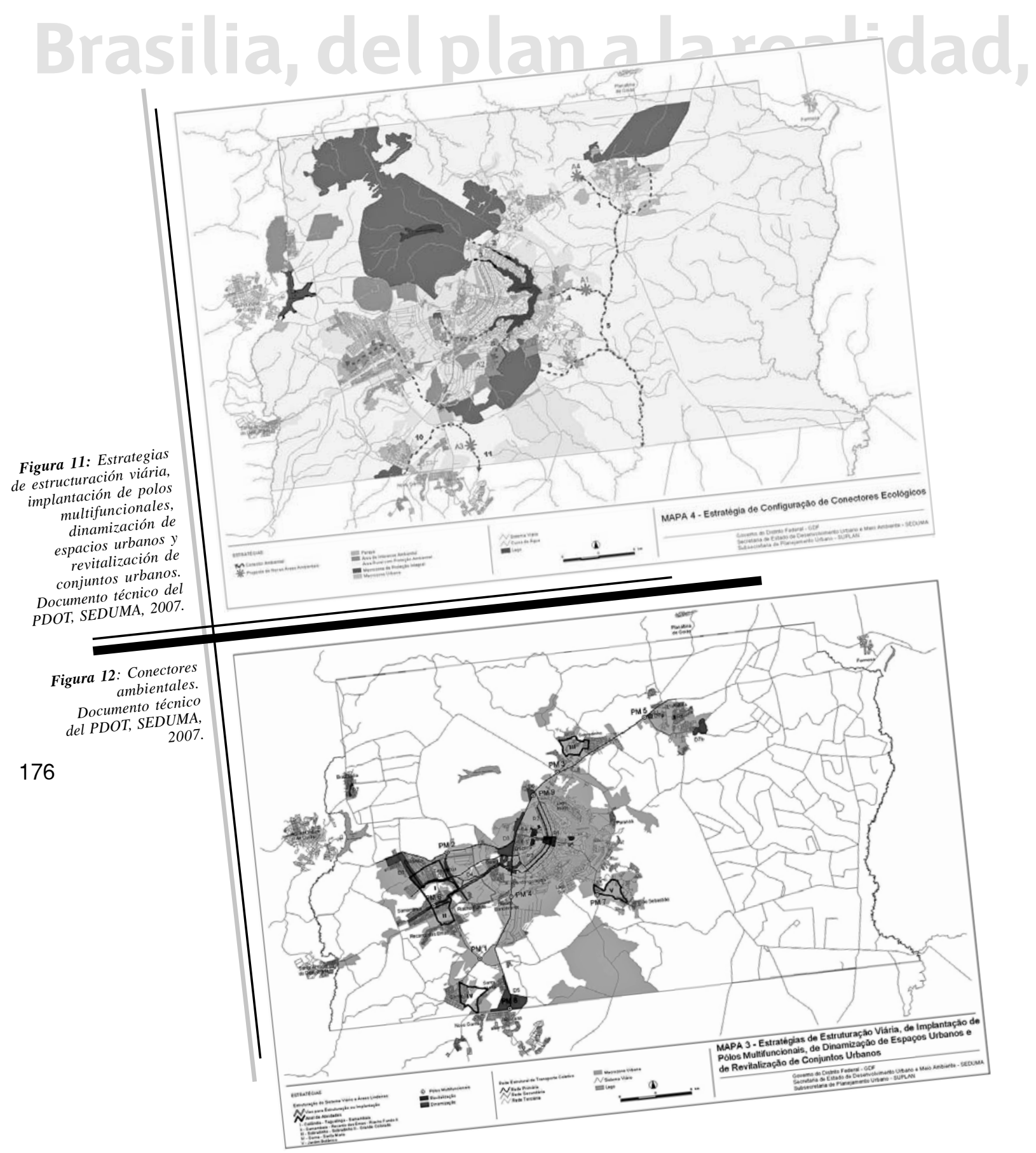




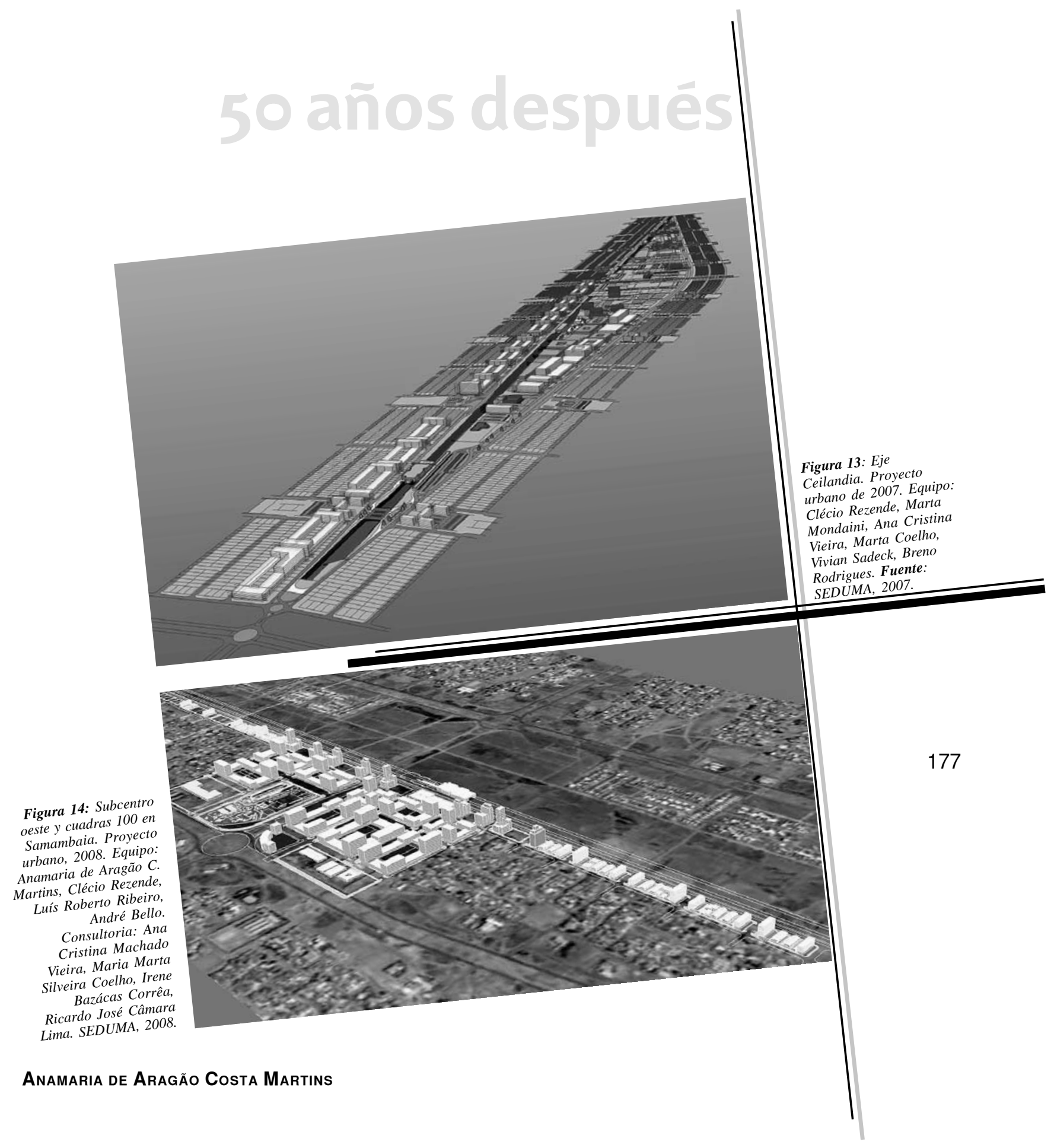




\section{Brasilia, del plan a la realidad,}

tensiones del tejido urbano consolidado. Así, se garantiza la optimización de la infraestructura de saneamiento instalada, que, dada la gran fragmentación del territorio, tiende a ser sub-aprovechada.

Las estrategias abarcan también las áreas de protección ambiental. Sobre el espacio natural, se identifican los principales conectores ambientales (figura 12), que garantizan los flujos bióticos, pues conectan las principales reservas ambientales (el Parque Nacional, Aguas Emendadas, la confluencia de las tres cuencas hidrográficas brasileñas, y el Área de Protección Ambiental Gama-Cabeça do Veado). En general se trata de espacios que acompañan cursos de agua y matas, cruzando los núcleos urbanos y haciendas. Deben materializarse como parques urbanos lineales en zonas urbanas, mientras que, cuando cruzan áreas rurales, serán definidos por ciclovías y senderos.

Además de intervenciones de escala territorial, se están desarrollando intervenciones locales. Por una parte, están las macro intervenciones sobre espacios vacantes de los núcleos urbanos, sean nuevos parques, centros y sub-centros urbanos o áreas a lo largo de infraestructuras. Son ejemplos:

* el eje Ceilandia: donde el metro implantado a nivel ha generado una gran ruptura y ha depreciado los valores de los inmuebles vecinos; el proyecto propone, la verticalización de las manzanas vecinas y crea un conjunto de actividades a lo largo de la infraestructura (figura 13);

* el sub-centro Oeste y cuadras 100 en la ciudad de Samambaia: propone la ocupación del espacio vacante a lo largo del metro, integrado con las funciones centrales del sub-centro; busca densidades altas y la mezcla de funciones; incluye un área destinada a deportes y recreación a ser concebida como un parque urbano (figura 14);

* el centro urbano de la ciudad de Recanto das Emas: propone, además de actividades con carácter cívico y administrativo, una zona de servicios y un área residencial, fomentando la mezcla de funciones (figura 15);

* el centro metropolitano, en la región más poblada de Brasilia: con su localización definida desde 1992, la idea del centro metropolitano sólo tomó forma con la decisión del gobierno actual de transferir la Administración Local a esta región, creando contra flujos que reduzcan los atascos del área central. El plan de ocupación integra el nuevo centro administrativo del gobierno local, con un nuevo campus de la Universidad de Brasilia; define un área residencial de alta renta y un área de vivienda social, además de un gran área terciaria y comercial, incluyendo hoteles, centros comerciales y equipamientos destinados a la celebración del carnaval, áreas para museos y teatros (figura 16).

Cuaderno Urbano. Espacio, Cultura, Sociedad -Vol. VII - № 7 (Octubre 2008) - pp. 165-182. ISnN 1666-6186 
Por otra parte, están las micro intervenciones sobre el espacio público, que califican las áreas que aún carecen de elementos de urbanización, tales como aceras, iluminación pública, arboriza-ción, ciclovías, etcétera.

Mientras las macro intervenciones locales se están desarrollando como proyectos urbanos, buscando integrar incluso el sector de la construcción civil, la idea de micro intervenciones ha orientado el formato de los planes locales. De una función eminentemente normativa, de regulación de usos, alturas, alineaciones, entre otras reglas de ocupación del suelo urbano, esos instrumentos pasarán a funcionar como pre-proyectos, definiendo las acciones necesarias para la implantación de dichos elementos de urbanización, las áreas prioritarias de intervención y los costes. Hasta el momento, se está desarrollando una experiencia con el núcleo urbano de São Sebastião, uno de los más recientes (figura 17).

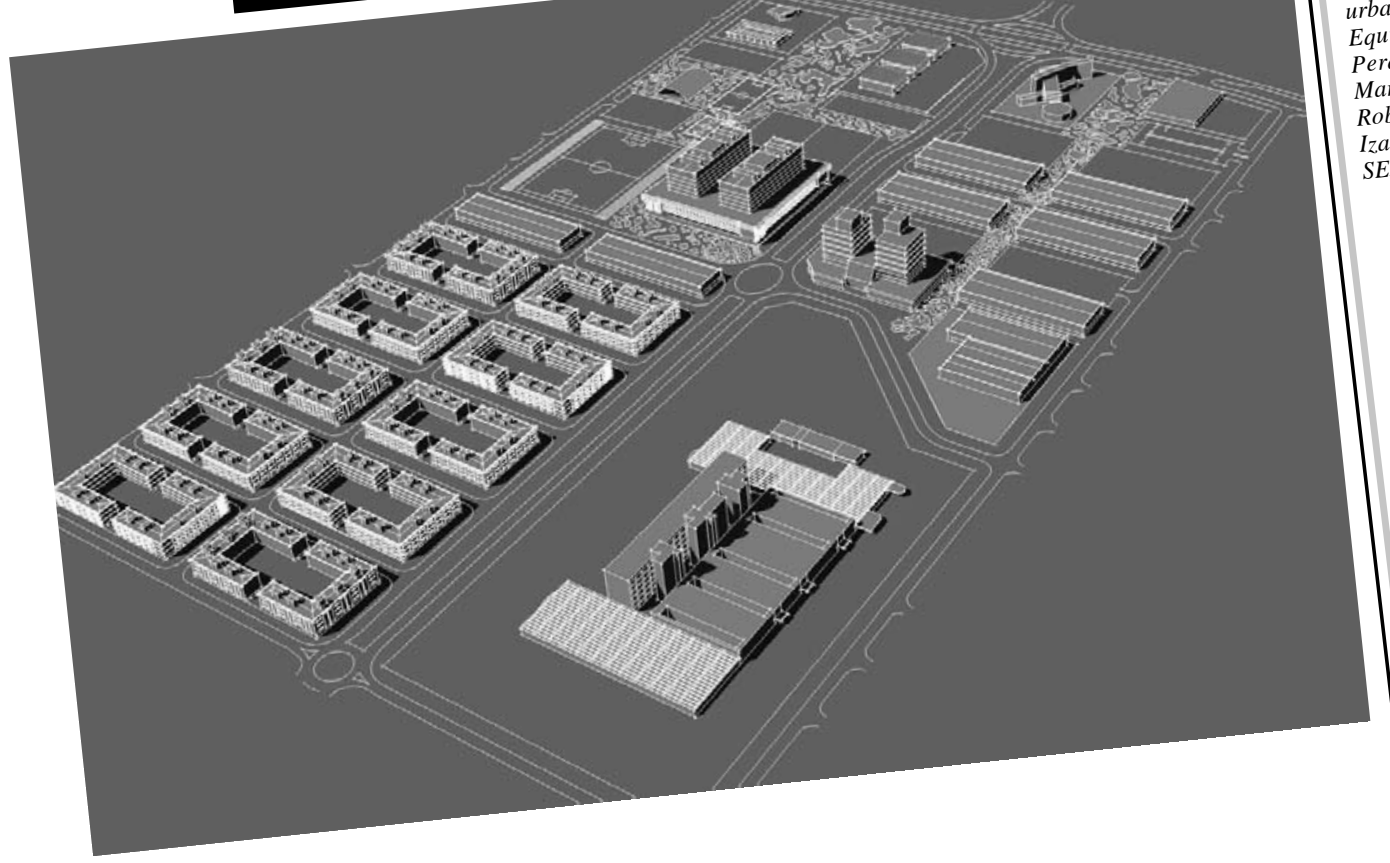

\section{Anamaria de Aragão Costa Martins}

Marques, Luís

Roberto Ribeiro,

SEDUMA, 2007. 


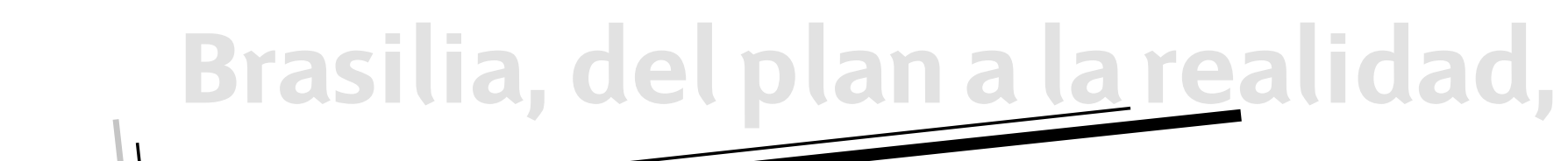

\section{CONSIDERACIONES FINALES}

Según datos de la Federación de Industrias de Brasilia (2008), Brasilia ha exportado cerca de US\$22 millones en enero de 2008. La industria contribuye significativamente con el comercio exterior. En 2003, se ha registrado que el sector terciario (comercio y servicios) contribuyó en 91,59\% del Producto Interno Bruto del Distrito Federal. Además, Brasilia ya es sede de 5 de las 10 más importantes empresas del ramo tecnológico.

Eso demuestra una diversificación en la economía de la capital brasileña que, desde su construcción, estuvo vinculada al rol de la Administración Pública y de la construcción civil, como actividades generadoras de empleo y renta.

Figura 16: Centro Metropolitano. Procente Lima Neto, Luis Silveira Coelho, Ire

Aragão C. Martins, Clécio Rezende, Vieira, Maria Marta Silveira, 2008.

Consultoria: Ana Cristina Machado José Câmara Lima. SEDUMA,

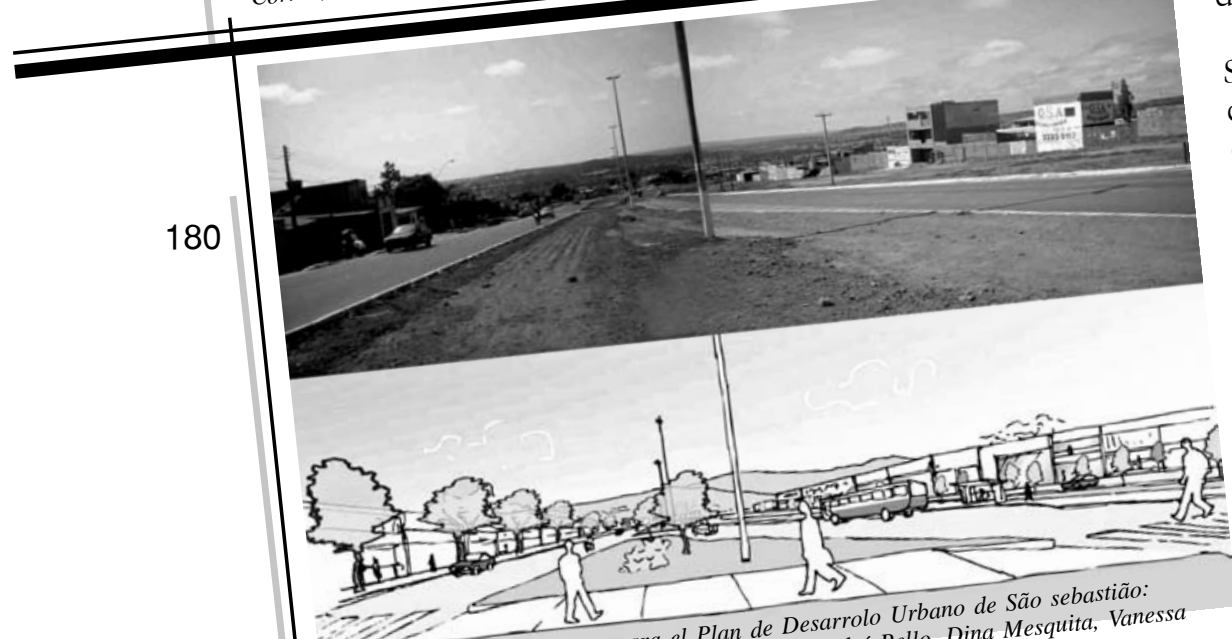

Se abren nuevas oportunidades para la ciudad capital, y muchas transformaciones vienen con este nuevo rol. Algunas de las áreas de dinamización propuestas en el Plan de Ordenación Territorial apuntan hacia este nuevo horizonte, como el Polo Capital Digital, dedicado a la tecnología, el fomento al puerto seco y al área industrial del Polo JK.

También se asume la realidad metropolitana como algo irreversible. Muchas voces sugieren que los problemas encontrados en Brasilia, muy parecidos a los de otras Fiura 17: Propuesta Piloto para

Proyecto urbano de 2007. Equipo: Hes. SEDUMA, 2007.

Zago, Breno Gomes, Rodro Urbano. Espacio, Cultura, Sociedad - Vol. VII - № 7 (Octubre 2008) - pp. 165-182. ISNN 1666-6186 
capitales, son consecuencia del aumento de la población. "iBrasilia ha sido planeada para 500 mil personas y hoy ya son más de dos millones!", dicen los críticos de los gobiernos pasados. "Hay que frenar las inmigraciones para que no venga más gente a vivir a la ciudad", dicen los defensores del medio ambiente.

Sin embargo, las tasas de inmigración decrecen en media $1 \%$ al año, demostrando que es el crecimiento vegetativo el principal motivo del aumento de la población.

Se planeaba que los que vendrían a construir Brasilia no se quedarían después de que el boom de la construcción finalizara. Del mismo modo, se esperaba que los funcionarios públicos, una vez jubilados, retornasen a sus estados de origen. Pero las familias han deseado quedarse y nuevas llegaron, atraídas por las oportunidades.

Brasilia crece porque ha dejado de ser sólo la sede de gobierno y se ha convertido en ciudad. Y, como todas las ciudades, tiene varias caras: la periferia emergente de empresarios y la periferia pobre de ciudades dormitorios, la Brasilia metropolitana y, lo que la diferencia, la Brasilia Patrimonio de la Humanidad. Pasados 50 años, es una ciudad que requiere adaptaciones del plan original y soluciones que puedan contribuir a su nueva condición.

\section{BIBLIOGRAFÍA}

BERTAUD, Alain (2001) The costs of utopia: Brasilia, Johannesburg and Moscow, en: http://alainbertaud.com.

BERTAUD, Alain. \& MALPEZZI, Stephen (2003) The Spatial Distribution of population in 48 World Cities: implications for Economies in transition, en: http://alain-bertaud.com.

BRASIL. IBGE (2000). Censo Demográfico 2000.

DIEESE - Departamento Intersindical de Estatística e Estudos Socioeconômicos (2006) Pesquisa de Emprego e Desemprego no Distrito Federal.

GDF. CODEPLAN (2000). Pesquisa Domiciliar de Transporte 2000.

GDF. SEDUH (2005) Estudo de demanda habitacional no Distrito Federal. Brasília: Metroquattro Arquitetura Tecnologia.

GDF. SEDUH; BIRD; CITIES ALLIANCE (2004) Macro análise do setor informal de habitação em Brasilia. Brasília.

GDF. SEDUH (2004) Modelo de gestão estratégica do território do Distrito Federal. Brasília: Metroquattro Arquitetura Tecnologia, 2004.

GDF. SEDUMA (2007) Documento Técnico do Plano Diretor de Ordenamento territorial, en: http:// pdot.seduh.df.gov.br.

FIBRA- Federação das Indústrias do Distrito Federal (2006) Plano Estratégico de Desenvolvimento Industrial do DF-2006/2015.

Anamaria de Aragão Costa Martins 


\section{Brasilia, del plan a la realidad,}

MANCINI, Gisele Arrobas (2008) Avaliação dos custos da urbanização dispersa no Distrito Federal. Tese de mestrado. Brasília, Universidade de Brasília.

MARTINS, Anamaria de Aragão C. (2006) "Novos pólos territoriais motivados pela dispersão urbana. O Caso do Distrito Federal" en: Arquitextos 077, texto especial 386, outubro de 2006, en: http://www.vitruvius.com.br/arquitextos/arq000/esp386.asp

MARTINS, Anamaria de Aragão C. (2007) "Vazios Urbanos em Brasília: espaços livres degradados, estacionamentos, lotes vazios, redes de infra-estrutura e setores em transformação influenciando a paisagem urbana da área tombada”, en GDF.SEDUMA (2007). Brasilía:50 anos. (no publicado)

MIRAGAYA, Júlio; CORDEIRO, Luís Alberto (1997). "Delimitação do Espaço Metropolitano de Brasília" en: Agora, Publicação da ASSIP, v. l, n. l.

PELUSO, Marília; CÂNDIDO, Washington (2005) Distrito federal: paisagem, população e poder. São Paulo: Harbra. 